\title{
Prácticas de Bioseguridad Adoptadas en Grandes Explotaciones de Bovinos de Carne de la Zona Central de Chile
}

\author{
Paris. A.; Maino, M.; Duchens, M. \\ Facultad de Ciencias Veterinarias y Pecuarias \\ Universidad de Chile
}

\begin{abstract}
Resumen
Bioseguridad se refiere al conjunto de acciones implementadas, orientadas a prevenir el ingreso y salida de agentes causantes de enfermedades en un área que se intenta proteger, así como también limitar su diseminación al interior de esta unidad.

El objetivo de este estudio fue definir especificaciones técnicas de bioseguridad predial para rebaños de bovinos de carne y determinar el nivel de cumplimiento de estas prácticas en explotaciones de bovinos de carne de la zona central.

Para ello se elaboró un Protocolo de Bioseguridad Predial, compuesto de 80 especificaciones técnicas. Este Protocolo fue evaluado mediante la aplicación de una encuesta en 10 planteles bovinos de producción de carne de ciclo completo con una masa superior a 1000 animales, ubicados en las regiones Quinta, Metropolitana y Sexta. La información obtenida se analizó en forma descriptiva y los resultados fueron expresados en porcentajes de cumplimiento. Los resultados obtenidos de este estudio indicaron que el 50,2\% de las especificaciones técnicas de bioseguridad descritas son aplicadas. El mayor nivel de cumplimiento se observó en la prevención de la diseminación de agentes causantes de enfermedades (64,8\%), observándose la aplicación de programas de vacunación y control de parásitos en la totalidad de los planteles. En la prevención de la salida de agentes causantes de enfermedades, se registró un nivel de cumplimiento del $40 \%$, detectándose como prácticas habituales el envío de animales enfermos hacia otros planteles. Se observó una reducida implementación de prácticas destinadas a prevenir el ingreso de agentes causantes de enfermedades (45,7\%), en especial en el ingreso de personas al plantel.

Se concluye que las explotaciones de bovinos de carne evaluadas tienen riesgo de introducir y diseminar agentes causantes de enfermedades que pueden afectar la salud animal y alterar la seguridad y calidad de un producto alimenticio.
\end{abstract}

Palabras clave: Bioseguridad, bovinos.

\section{Introducción}

Bioseguridad se define como el resultado de las estrategias implementadas en una unidad productiva, destinadas a prevenir la introducción y la salida de agentes patógenos o toxinas que tienen el potencial de dañar la salud de un rebaño y/o alterar la calidad y seguridad de un producto alimenticio (Sanderson et al., 2000; Radostits, 2003; Dargatz et al. 2002). Las acciones destinadas a prevenir la diseminación de enfermedades o intoxicaciones al interior de esta unidad productiva se denomina biocontención (Brandt et al. 2008). Para el propósito de este estudio el término bioseguridad es utilizado en sentido genérico englobando ambos conceptos.

La aparición de brotes de enfermedades animales de gran trascendencia, como fiebre aftosa y encefalopatía espongiforme bovina, en Reino Unido y Estados Unidos, ha incrementado la preocupación en desarrollar estrategias para controlar y erradicar las enfermedades infecciosas de los animales, posicionando a la bioseguridad 
como una herramienta esencial en la comercialización de productos en mercados externos (Brandt et al. 2008).

Desde el punto de vista de la medicina productiva, la bioseguridad participa activamente en la prevención de enfermedades en animales productores de alimentos, principalmente debido a que las enfermedades animales reducirán la productividad y/o serán perjudiciales para el bienestar animal (Radostits 2003).

Por otra parte, los consumidores están cada vez más preocupados con la higiene y la calidad de los productos alimenticios (Radostits, 2003) En especial con la asociación de peligros biológicos específicos para la población humana, con alimentos de origen animal, lo cual ha enfocado la atención de los consumidores con el manejo de las prácticas de manejos de los animales (Brown et al. 2001) En ese sentido, la bioseguridad tiene como objetivo principal proteger la cadena de alimentos del hombre (Radostits, 2003).

La bioseguridad, entonces, se posiciona como una herramienta que permite mantener e incrementar el status sanitario de los rebaños productivos, y asegurar la calidad sanitaria de los productos derivados de estos sistemas. Por lo tanto, para asegurar un desarrollo exportador sustentable sobre la base de la calidad sanitaria de los productos de carne bovina nacional, es fundamental implementar prácticas de bioseguridad en los planteles de bovinos de carne nacionales.

El propósito de este estudio es entregar pautas de bioseguridad que sirvan de apoyo para los sistemas de producción de bovinos de carne nacionales, mediante la elaboración de un Protocolo de Bioseguridad Predial. Asimismo, identificar las prácticas de bioseguridad que se han implementado en grandes explotaciones de carne bovina de la zona central, y de esta manera informar acerca de las principales fortalezas y deficiencias de estos sistemas, respecto a la bioseguridad predial.

\section{Materiales y Métodos}

El Protocolo de Bioseguridad Predial para sistemas productivos de carne bovina se elaboró mediante una revisión bibliográfica de los principios básicos y prácticas de bioseguridad predial implementadas en los principales países productores de carne bovina. Esta información se integró a los sistemas productivos de carne bovina nacional, por medio de una consulta a expertos del área de medicina productiva del bovino y a profesionales del Servicio Agrícola y Ganadero.

La identificación del nivel bioseguridad predial, se realizó mediante la elaboración de una encuesta predial, en base a 110 preguntas cerradas, la cual se constituyó en base a dos módulos, i) información básica del predio y ii) Check list de prácticas de bioseguridad predial.

El módulo check list se constituyó en base a 3 secciones: Prevención en el ingreso de agentes causantes de enfermedades al predio; Prevención en la diseminación de agentes causantes de enfermedades en el predio; Prevención en la salida de agentes causantes de enfermedades.

La población objetivo de este estudio correspondió a planteles de bovinos de carne de ciclo productivo completo, con una masa ganadera superior a 1000 animales, pertenecientes a las regiones Quinta, Metropolitana y Sexta. A nivel nacional se identificó una población de 279 predios con estas características, de los cuales 18 planteles pertenecían a las regiones Quinta, Metropolitana y Sexta. De acuerdo a la metodología aplicada, el tamaño de muestra obtenido correspondió a 10 predios.

Los planteles fueron identificados a partir del listado de clientes de una empresa de servicios veterinarios e información proveniente de asesores prediales de la zona. Las encuestas fueron realizadas a modo de entrevista personal realizada en el predio, la cual fue contestada por el administrador o productor, según el caso. Las respuestas fueron completadas y corroboradas con la información obtenida a través de la visita al plantel.

El cálculo del tamaño de la muestra se ejecutó en base a la estimación de porcentajes, utilizando un nivel de confianza del 95\%, con un error estimado del $10 \%$ y basándose en que una proporción del 95\% de los predios cumple con las especificaciones de bioseguridad. El cálculo estadístico se realizó mediante el programa computacional Win Episcope 2.0. 


\section{Resultados}

El Protocolo de Bioseguridad Predial se conformó en base a 80 especificaciones técnicas agrupadas en tres ítems: Prevención en el ingreso de agentes causantes de enfermedades al predio, Prevención en la diseminación de agentes causantes de enfermedades en el predio y Prevención en la salida de agentes causantes de enfermedades. Lo cuales a su vez se dividieron en 12 subítems, como se presenta en el anexo 1.

\subsection{Caracterización de la muestra}

La encuesta fue realizada en 10 explotaciones de bovinos de carne ubicadas en las regiones V, RM y VI. Los planteles evaluados, presentaron una masa ganadera promedio de 1.246 animales, con un rango de 1.000 a 3.000 animales. La superficie promedio de los predios ascendió a 2.133 ha, presentando un valor mínimo de 670 ha y un valor máximo de 10.000 ha. La totalidad de los predios evaluados, realizaban el ciclo completo de producción.

El 80\% de la muestra (8/10) presentó un sistema de estabulación mixto, el $10 \%$ (1/10) utilizaba sólo las praderas y el otro 10\% (1/10) mantenía a los animales sólo en confinamiento. El 50\% de la muestra (5/10) se encontraba suscrito al programas de certificación PABCO (Planteles Animales Bajo Control Oficial), de los cuales 4 pertenecían al nivel B y uno al A (SAG, 2010c).

Se determinó el porcentaje de planteles que implementaron las prácticas de bioseguridad predial, de acuerdo a los ítems descritos.

\subsection{Prevención en el ingreso de agentes causantes de enfermedades al predio}

La principal política de bioseguridad es mantener un rebaño cerrado o tener un control estricto de las incorporaciones animales al plantel (Radostits, 2003; Wells et al. 2002). Los resultados obtenidos indican que la introducción de animales al rebaño se realizó en $100 \%$ de los predios (10/10). En cuanto al origen de los animales introducidos, la mayor parte correspondió a otros predios, identificándose sólo 2 predios que introdujeron animales desde ferias $(20 \% ; 2 / 10)$.
La principal categoría incorporada correspondió a toros, observándose su ingreso en la totalidad de los planteles evaluados (100\%; 10/10). La incorporación de toros es realizada con la finalidad de incorporar genética al rebaño, no obstante, el ingreso de toros al rebaño como cualquier animal al predio está asociado al riesgo de introducir enfermedades a la población (Radostits, 2003; Sanderson y Gnad, 2002). El uso de inseminación artificial como una alternativa complementaria al uso del toro, se evidenció en 9 predios. Esta es una práctica que reduce los riesgos de introducir agentes patógenos, si se utiliza material genético de reproductores con certificación sanitaria (Radostits, 2003).

El conocimiento de la situación sanitaria de los animales previa incorporación al rebaño es una de las herramientas más importantes para prevenir el ingreso de agentes patógenos no deseados al plantel (Sanderson y Gnad, 2002). Al respecto, en 7 predios $(70 \% ; 7 / 10)$ se indagó sobre la condición sanitaria del plantel, mediante consulta al veterinario del rebaño de origen, manifestándose sólo interés respecto a las enfermedades de control oficial.

La mantención de los cercos y deslindes en buen estado tiene como objetivo evitar cualquier contacto de los animales, con ganado con status sanitario desconocido y ganado enfermo (Crawshaw et al. 2002). En 7 predios (7/10) los cercos y deslindes del plantel se mantenían en buen estado, no obstante, el impedimento del contacto naso-nasal a través de los deslindes, no se registró en ningún plantel. Respecto a la realización de pastoreos comunitarios con rebaños de otros predios, no se registró dicha práctica como parte del manejo habitual.

\subsection{Cuarentena}

Se denomina cuarentena a un lugar o a un período fijo de aislamiento, o a la restricción del movimiento de animales. El objetivo de la cuarentena es disminuir la probabilidad de introducir ciertas enfermedades al rebaño residente, principalmente enfermedades de períodos de incubación reducidos (Radostits, 2002; Sanderson et al. 2000; Callan y Garry, 2002). Al respecto, en $60 \%$ de los predios (6/10) 
se realizó el aislamiento de la totalidad de los animales introducidos.

En los predios que realizaron cuarentena, sólo en el 50\% (3/6) se identificó una instalación que permite un aislamiento efectivo del rebaño del predio. El cual corresponde a un corral ubicado en una zona de bajo tráfico animal y humano, alejado de las instalaciones animales, que impida el contacto naso-nasal y en lo posible evite utilizar espacios que compartan el aire entre rebaños (Crawshaw et al. 2002; Callan y Garry, 2002). La situación observada en los plateles bajo estudio, reduciría la efectividad de la instalación de aislamiento, permitiendo la transmisión de agentes patógenos por contacto directo entre animales.

La observación y revisión regular de los animales bajo cuarentena, se observó en 2 planteles (33,3\%; 2/6). La evaluación de los animales bajo cuarentena permite detectar tempranamente sintomatología clínica de enfermedades agudas y consiste en la evaluación de la actitud del animal, el apetito, la consistencia fecal y la temperatura rectal, entre otras pruebas (Wells et al., 2002). Respecto a la realización de exámenes diagnósticos durante este período, no se observó en ningún plantel. El reducido interés por establecer el estatus sanitario por medio de observación y/o exámenes diagnósticos, se podría atribuir a que la indagación de la condición sanitaria del predio de origen es considerada suficiente para reducir el riesgo de incorporar agentes patógenos, lo cual desde el punto de vista de bioseguridad es incompleto.

La aplicación de programas de vacunación y desparasitación, antes de incorporar las adiciones al rebaño residente, es realizada en la totalidad de los predios (100\%; 10/10). El objetivo de esta práctica durante el período de cuarentena, es proporcionar un estatus inmune similar al del rebaño residente, y de esta forma evitar que las enfermedades afecten al rebaño que se incorpora como al residente (Radostits, 2003; Wells et al., 2002). La realización de esta práctica en la totalidad de los predios evaluados, podría ser indicativo de que la aplicación de programas de vacunación es considerada una práctica suficiente en reducir el riesgo de incorporar enfermedades al rebaño, lo cual es limitado debido a que no todos los animales de un rebaño responden de igual manera frente a la inmunización, y además existe información limitada respecto a la efectividad de las vacunas (Sanderson et al. 2000). Respecto a la limpieza del establecimiento de cuarentena, en el $50 \%(3 / 6)$ se realiza una remoción de estiércol y restos de alimento una vez finalizado el período de aislamiento. Esta medida tiene como finalidad evitar que el ganado que se incorpora en forma posterior esté en presencia de agentes patógenos, ya que existe evidencia científica que agentes como Salmonella spp. y $M$. paratuberculosis, pueden sobrevivir días en el estiércol (Wells et al. 2002; Stabel, 1997).

\subsection{Ingreso de personas al predio}

Existe riesgo de introducción de enfermedades a través de personas, en especial personal asociado a las explotaciones animales, ya que pueden transportar agentes dañinos al rebaño a través de sus ropas y calzado (Crawshaw et al. 2002). Al respecto, en los predios bajo estudio, se observó la existencia de un acceso restringido en 5 predios (50\%; 5/10). En 2 planteles (20\%; 2/10) se observó sistemas de pediluvios en el ingreso a la explotación y en 2 predios (20\%; 2/10) se registro la exigencia de ingresar a la explotación con ropas y calzado limpio. Respecto a la restricción del contacto de las personas con los animales y el alimento de los animales del plantel, se observó que en ningún plantel se implementa esta restricción. Esta práctica está destinada a prevenir la transmisión de agentes patógenos provenientes del estiércol y evitar la contaminación del alimento (Brandt et al, 2008).

La reducida adopción de prácticas de bioseguridad en el ingreso de personas se atribuiría al desconocimiento que poseen los encargados de los predios y en especial, el personal asociado a las explotaciones animales, respecto al riesgo que poseen en la diseminación de enfermedades.

\subsection{Ingreso de vehículos}

De acuerdo a los antecedentes recolectados, en 5 predios (50\%; 5/10) se observó un acceso vehicular restringido y en 8 planteles (80\%; 8/10) se detectó un área de estacionamiento de vehículos, ubicado en la periferia de la explotación. 
La existencia de un proceso de desinfección para vehículos en el acceso al plantel se observó 2 predios (20\%). Esta instalación tiene la finalidad de reducir el riesgo de ingresar agentes patógenos por medio del estiércol y materia orgánica adherida, como es el caso del virus de la Fiebre Aftosa, el cual puede sobrevivir por varios días en el estiércol (Bartley et al, 2002).

La ubicación del cargadero y su respectivo corral en la periferia del plantel se observó en el en el $50 \%$ de la muestra. Esta medida es relevante, ya que los animales durante el transporte podrían incrementar la diseminación de agentes como $E$ coli 0157 y Salmonella spp., los cuales tienen la capacidad de sobrevivir por periodos prolongados en este ambiente (Brandt et al 2008; Bach et al. 2004). Existe un grado aceptable de la mayoría de las medidas evaluadas, a excepción de la existencia de un proceso de desinfección, sin embargo esta deficiencia se compensa con la existencia de acceso restringido y estacionamientos en la periferia, lo que disminuiría el riesgo de ingreso de agentes patógenos.

\subsection{Prevención en la diseminación de agentes causantes de enfermedades en el predio}

\section{Manejo Sanitario}

En relación a los manejos sanitarios realizados en los predios bajo estudio, el desarrollo y aplicación de un programa de vacunación y de control de parásitos se registró en 9 predios (90\%; 9/10). Respecto a las principales enfermedades que se incluyen en los programas de vacunación se observa, Clostridiosis (100\%), Brucelosis (70\%), Carbunclo Bacteridiano (70\%). La proporción de predios que vacuna contra enfermedades clostridiales se explica debido a que es una efectiva medida de control, que a su vez es de bajo costo (Dargatz et al, 2002). Respecto a la vacunación contra brucelosis, se atribuye a la existencia del programa oficial de erradicación a cargo del Servicio Agrícola y Ganadero (SAG, 2004d). Destaca la baja proporción de predios que vacuna contra enfermedades que generan importantes problemas reproductivos, como Rinotraqueitis Infecciosa Bovina (RIB) y Diarrea Viral Bovina (DVB), que según Radostits (2003) deben estar dentro de un plan de vacunación de un plantel vaca-cría.
Respecto al diagnóstico de las enfermedades existente, se identificó que los predios evaluados realizaron el diagnóstico de Brucelosis (50\%), Campilobacteriosis (20\%) y Tricomoniasis (20\%). La información recolectada indica que existe un bajo interés en establecer el estatus sanitario del rebaño, sólo se observa mayor interés respecto a brucelosis, principalmente por la existencia del Programa Oficial de Erradicación de Brucelosis Bovina, el cual exige la realización de vacunaciones y muestreos de los animales (SAG, 2004d). El uso de agujas y jeringas desechables, en forma individual, se registró en 6 predios evaluados (60\%; 6/10). Esto en importante, en especial en agentes infecciosos que pueden ser transferidos de animal a animal durante procedimientos de rutina, transportados en pequeñas cantidades de sangre, como es el caso de la Leucosis Bovina (Radostits, 2003)

Manejo de animales enfermos. La segregación de animales enfermos para prevenir la exposición directa del rebaño sano a patógenos, es la base del control de la transmisión de agentes endémicos (Brandt et al, 2008, Wells et al., 2002, Callan y Garry, 2002). Al respecto, la separación de los animales que presentan signos clínicos del rebaño o del grupo original en un área especial o corral de enfermería, se realizó en 9 predios (90\%; 9/10).

La separación y asilamiento efectivo de estas instalaciones, de forma que se impida el contacto entre animales, se detectó en 4 predios (44\%; 4/9). La aplicación de esta medida es fundamental debido a que una distancia superior a 3 metros de separación de los corrales puede reducir significativamente el riesgo de transmisión de diversos agentes patógenos, como DVB e RIB (Crawshaw et al., 2002). La utilización de materiales y equipos reutilizables en el tratamiento de animales enfermos involucra un importante riesgo de transmitir agentes patógenos entre animales, al estar éstos en contacto con secreciones corporales como estiércol, orina, saliva, secreciones respiratorias, entre otras (Radostits, 2003, Brandt et al 2008). En los predios bajo estudio la limpieza y desinfección de materiales utilizados en el tratamiento de los animales enfermos se observó en 9 predios (90\%; 9/10).

Manejo de animales muertos. En los predios evaluados, los animales muertos son removidos en menos de 48 horas posterior a su muerte del lugar 
donde fallecieron en 9 predios (90\%; 9/10). La eliminación de los animales muertos se realizó mediante el entierro de los animales en una fosa alejada de las instalaciones del rebaño. Esta situación sería indicativa de que en los predios están conscientes del riesgo que presentan los cadáveres de animales en la transmisión de enfermedades.

\section{Manejo de alimento}

El alimento puede transformarse en una fuente de infección, principalmente a través de la contaminación fecal; proveniente de animales del predio, roedores, aves y moscas, los cuales pueden infectar el alimento por medio de sus propias heces o servir de vector mecánico (McGuirk, 2002; Daniels et al. 2003). Es por ello que el almacenamiento de los insumos alimenticios debe realizarse en lugares cerrados, protegidos de la luz, la humedad y de los animales silvestres. En los predios bajo estudio esta práctica se realiza en el $70 \%$ de la muestra $(7 / 10)$

La realización de una adecuada inspección a las partidas de alimento considera la detección de colores y olores inusuales, temperatura elevada, exceso de humedad y presencia de hongos y de material extraño, esta práctica se desarrolló en 5 predios (50\%; 5/10).

Respecto de la utilización de alimentos con harina de carne y huesos de origen rumiante, no fue detectada en este estudio. Situación que coincide con las normativas actuales del Servicio Agrícola y Ganadero (SAG, 2005a). En cuanto al uso del guano de pollo y/o cerdo como insumo alimenticio, en 9 predios (90\%; 9/10) se observó esta práctica. Esta elevada utilización se explica debido a que el guano de pollo es una fuente de proteína, rica en minerales esenciales, de bajo costo. No obstante, si no es procesada correctamente, esta proclive al crecimiento de organismos patógenos y a la presencia de residuos farmacéuticos (Jefrey et al, 1998). La limpieza de los bebederos se efectuó en forma semanal y la limpieza de los comederos se realizó en promedio cada 4,6 días. La limpieza de comederos y bebederos en forma regular, tiene como objetivo prevenir la potencial contaminación, desarrollo y mantención de agentes patógenos (Wells et al., 2002). En general, los antecedentes recolectados indican que existe preocupación por el manejo de alimentación de los animales, no obstante esto se atribuiría a los costos de producción que representa la alimentación en un sistema productivo, lo que sin duda genera mayor interés en el aspecto sanitario de los alimentos.

\section{Manejo preventivo de enfermedades}

Presencia de otra especia animal. La presencia de otras especies de animales puede infectar directamente al ganado o simplemente transportar agentes patógenos mecánicamente de un lugar a otro. Ejemplos de aquello, incluyen Salmonella en aves domésticas y Leptospira en roedores y Neospora en perros. (Radostits, 1999; Wells et al 2002). Los resultados de este estudio arrojaron que en la totalidad de los predios encuestados se detectó la presencia de animales domésticos y de producción. Las especies que se encontraron con mayor frecuencia correspondieron a perros y a caballos. Estos resultados demuestran que las especies animales no son consideradas como un potencial riesgo para la salud del rebaño.

Manejo de grupos de producción: Establecer grupos de producción estables, evitando realizar introducciones e intercambio de animales desde otros grupos, reduce la entrada de agentes infecciosos desde otros grupos de producción, los cuales pueden tener una situación sanitaria diferente (Wells et al., 2002). Esta práctica es realizada en la totalidad de los predios $(100 \%$; 10/10). La agrupación de los animales se desarrolla una vez que los animales son destetados y en la mayoría de los predios se realiza de acuerdo al peso de los animales.

Manejo reproductivo. El traslado de las hembras que están próximas a parir a potreros aislados del resto del rebaño y destinados exclusivamente para dicho fin, es realizado en todos los predios bajo estudio $(100 \% ; 10 / 10)$. La finalidad de esta práctica es reducir la exposición de agentes patógenos a los terneros, manejar las condiciones estresantes que pueden alterar la respuesta inmune, y permitir una observación de las hembras en caso de que se desarrollen alteraciones durante el parto (Barrington et al, 2002; Wells et al. 2002) 
Paris A. et al.

\section{Control de Plagas}

El control de moscas es fundamental para reducir la transmisión de enfermedades como la queratoconjuntivitis infecciosa bovina, enfermedades transmitidas a través de la sangre, fecas y reducir el estrés (Barrington et al. 2002). De la totalidad de la muestra, en 6 predios $(60 \%$; 6/10) se realizó el control de las moscas, los métodos utilizados correspondieron a la aplicación de insecticidas tópicos y productos ambientales. El control de roedores se realizó en 6 explotaciones (60\%; 6/10) por medio de veneno y la presencia de gatos. La presencia de roedores en un predio bovino puede generar importantes problemas sanitarios, al contaminar el alimento con sus deposiciones situación involucrada en la transmisión de la Leptospira, Salmonella y E. Coli (Daniels et al. 2003; McGuirk, 2002). Los resultados indicarían que los productores reconocen el rol que poseen estas especies en la transmisión de enfermedades. Se identifica en especial, a moscas y roedores, como portadores de agentes infecciosos perjudiciales para el ganado.

\section{Manejo de estiércol}

En los predios que realizan confinamiento de animales, se evidenció que el estiércol es removido en forma periódica en el $100 \%$ de los predios que realizan confinamiento (9/9). La remoción rutinaria del estiércol tiene como objetivo prevenir el desarrollo y mantención de agentes patógenos como $M$. avium subsp paratuberculosis y Salmonella spp, los cuales tienen la capacidad de sobrevivir en este ambiente por varios meses, y asimismo interferir con el desarrollo de ciclo de vida de parásitos (Wells et al., 2002; Stabel 1997).

La utilización de este elemento como fertilizante para las praderas se observó en 9 explotaciones, no obstante, solo en 6 predios es sometido a un proceso de estabilización antes de utilizarlo para dicho fin. Esta situación es relevante ya que la aplicación inmediata del estiércol como fertilizante a los suelos sin la realización de un período de tratamiento, involucra un importante riesgo de contaminación con agentes patógenos, debido a que la carga de patógenos no decrece (Wells et al., 2002; Nicholson, 2005).

\section{Manejo de maquinaria y equipos}

La maquinaria utilizada en las faenas del plantel es propia y de uso exclusivo por el plantel en 8 predios $(80 \%$; 8/10). La utilización de maquinaria exclusiva para realizar las tareas de alimentación se observó en 9 predios (90\%; 9/10). Esta situación se atribuye al tamaño de las explotaciones y nivel productivo.

Al utilizar la maquinaria de alimentación en forma exclusiva para dicho fin, se reduce considerablemente el riesgo de que patógenos del estiércol y animales muertos contaminen el alimento por esta vía. La transmisión de agentes como DVB, Escherichia coli O157 y Salmonella spp. pueden favorecerse por estas prácticas (Sanderson et al, 2000; Brandt et al, 2008). La limpieza y desinfección rutinaria de los equipos y maquinaria empleada para la remoción de estiércol y animales muertos, se observó en 4 predios, $(40 \% ; 4 / 10)$. Esta situación es relevante ya que al no existir un proceso de desinfección posterior al manejo de animales muertos no se reduce la carga de patógenos, existiendo un gran riesgo de diseminar agentes patógenos al emplear la maquinaria en el plantel (Sanderson et al. 2000).

\section{Prácticas de trabajadores}

Los trabajadores al ingresar al plantel, cambian sus ropas por ropas de trabajo exclusivos del plantel en el $70 \%$ de los predios evaluados. Respecto la existencia de un lugar específico para el lavado y limpieza de botas y manos, esta medida se observó en 9 predios.

Estas medidas reducen significativamente el riesgo de transmitir agentes patógenos al rebaño, al evitar el ingreso de calzados y ropas posiblemente contaminados. Es de especial importancia el lavado de botas, el cual tiene como objetivo remover la mayor cantidad de materia orgánica adherida y tiene especial importancia en el manejo de animales enfermos ya que éstos diseminan cantidades altísimas de agentes patógenos (Brandt et al. 2008). 


\subsection{Prevención en la salida de agentes causantes de enfermedades del predio}

\section{Salida de animales y vehículos del predio}

En los predios evaluados, la salida de animales enfermos se realizó hacia ferias de ganado, matadero y a otros predios. Esta información es de gran relevancia, ya que los animales enfermos poseen una gran capacidad de diseminar agentes causantes de enfermedades (Brandt et al 2008; Callan y Garry, 2002), lo cual adquiere mayor importancia cuando se envían a estos animales hacia otras instalaciones animales.

La realización de un proceso de lavado y desinfección a los vehículos que abandonan el plantel, con el objeto de eliminar estiércol u otras secreciones depositadas en el vehículo, es realizado en 2 planteles (20\%; 2/10). Esta medida evita que las zonas del vehículo contaminadas accidentalmente con materia orgánica sean fuente de diseminación agentes causantes de enfermedades en el trayecto y destino del vehículo. Al respecto, el SAG implementó un programa de Bioseguridad en Recintos Feriales, que tiene como finalidad reducir la carga de microorganismos en los vehículos que ingresan y salen de las ferias de ganado, mediante un proceso de lavado y desinfección obligatorio (SAG, 2006b).

Existe un bajo conocimiento del riesgo que implica el envío de animales enfermos hacia otra explotación animal, el factor económico prevalece sobre el factor sanitario, que se traduce en recuperar en parte la inversión del animal al enviarlo a feria o venderlo a terceros, lo que dificulta la adopción de estas medidas.

En resumen, las especificaciones técnicas de bioseguridad son una herramienta valiosa desde la perspectiva de la sanidad animal, ya que permiten disminuir considerablemente el impacto que poseen las enfermedades del rebaño en los sistemas productivos de bovinos de carne de la zona central, a través de la realización de modificaciones e innovaciones en los manejos habituales del rebaño.

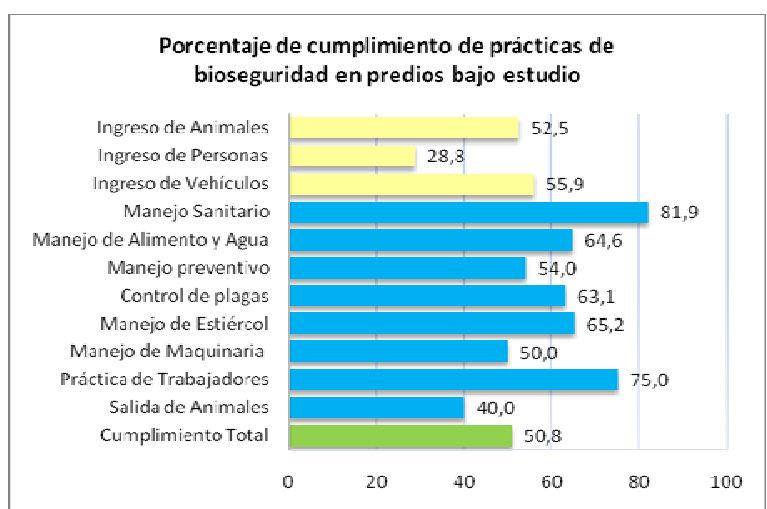

Gráfico: Nivel de cumplimiento de prácticas de bioseguridad en los predios bajo estudio, según subítems, ítems y total, de acuerdo al porcentaje de cumplimiento.

\section{Conclusiones}

En los sistemas productivos de carne bovina evaluados de la zona central de Chile, pertenecientes a la categoría de grandes productores, se cumple el $50,8 \%$ de las especificaciones técnicas de bioseguridad.

El ingreso de animales al rebaño es una práctica habitual de todos los predios bajo estudio, en donde la realización de los manejos sanitarios del predio residente a los animales introducidos, corresponde a la principal práctica de bioseguridad realizada para prevenir el ingreso de agentes patógenos al rebaño.

El ingreso de personas al predio alcanzó el menor nivel de cumplimiento (28,8\%), principalmente a raíz del bajo número de predios que exige el ingreso de personas al plantel, con calzado y vestimenta limpia; y debido al contacto que mantienen las personas ajenas, con los animales, sus alimentos y agua, y el estiércol.

El mayor nivel de cumplimiento alcanzados corresponde a la realización de las prácticas de bioseguridad de manejo sanitario (81,9\%), principalmente producto de la alta proporción de predios presenta programas de vacunación y de control de parásitos; al adecuado manejo de los animales enfermos y una rápida y correcta remoción y eliminación de los animales muertos.

El ítem de manejo de alimentos y agua obtuvo un nivel de adopción de 64,6\%, lo cual se atribuye 
mayormente al alto número de predios elabora una ración balanceada, almacena los alimentos en lugares cerrados y protegidos y utiliza fertilizantes y plaguicidas correctamente.

La salida de animales y vehículos alcanzó sólo el $40 \%$ de adopción, uno de los ítems con menor cumplimiento, principalmente a raíz de la salida habitual de animales enfermos del plantel con destino a otros predios y ferias de ganado; y a la falta de un proceso de desinfección vehicular en la mayoría de los predios.

Finalmente, se concluye que existen oportunidades para mejorar la bioseguridad predial en grandes explotaciones de ganado de carne de la zona central, las cuales se deben sustentar sobre la base de la entrega de conocimientos a profesionales, técnicos y productores del sistema.

\section{Referencias}

1. Bach, S.J.; Mccallister, T.A., Mears, G.J., 2004. Long-haul transport and lack of preconditioning increases fecal shedding of Escherichia coli and Escherichia coli O157:H7 by calves. J Food Prot 67:672678.

2. Barrington, G. M.; Gay. J. M.; Evermann, J. F. 2002. Biosecurity for neonatal gastrointestinal diseases. Vet. Clin. North. Am. Food. Anim. Pract. 18: 7-34

3. Bartley, L.M.; Donnelly Ca, Anderson Rm. 2002. Review of foot-and mouthdisease-virus survival in animal excretions and on fomites. Vet Rec; 151:667-669

4. Brandt, M.; El W. Sanderson, M.W.; Degroot, B.D.; Thomson,D.U.; Hollis, L.C. 2008. Biocontainment, biosecurity and security practices in beef feedyards. JAVMA, 232( 2): 262-269.

5. Brown, P.; Will, R.G; Bradley, R.; Asher, D.M.; Detwiler, L. 2001.Bovine Spongiform encephalopathy and variant Creutzfeldt-Jacob disease: Background, evolution and current concerns. Emerg. Infect. Dis. 7:6-14

6. Callan, R.; Garry, B. 2002. Biosecurity and bovine respiratory disease. Vet. Clin. North. Am. Food. Anim. Pract. 18: 5577.

7. Crawshaw, M.; Caldow, G.; Gunn, G.; Rusbridge, S. 2002. Technical note T502: Herd Biosecurity for Cattle. Edinburgh, Scottish Agricultural College. [En línea] <http://www.sac.ac.uk> [Consulta 25-10-2010]

8. Jeffrey, J.S.; Kirk, J.H.; Atwill, E.R.; Cullor, J.S. 1998. Research notes: Prevalence of selected microbial pathogens in processed poultry waste used as dairy cattle feed. Poultry Science, 77(6): 808-811.

9. Dargatz, D. A.; Garry, F. B.; TraubDargatz, J. L. 2002. An Introduction to biosecurity of cattle operations. Vet. Clin. North. Am. Food. Anim. Pract. 18: 1-5.

10. Daniels, M.J.; Hutchings, M.R.; Greig, A. 2003. The risk of disease transmission to livestock posed by contamination of farm stored feed by wildlife excreta. Epidemiology and Infection (2003), 130: 561-568

11. McGuirk, S. M. 2002. Forage feeding and biosecurity issues for cattle. School of Veterinary Medicine. University of Wisconsin-Madison. [En línea] <http:// www.uwex.edu/ces/forage/wfc/.../biosec urity.doc> [Consulta 08-01-2011]

12. Nicholson, F.A., 2005. Pathogen survival during livestock manure storage and following land application. Bioresource Technology. 96: 135-143

13. Radostits, O. 2003. Principios de bioseguridad para la producción de carne y leche. In: V Simposio Internacional de Reproducción Animal. Córdoba, Argentina. 27, 28 y 29 de Junio 2003. Instituto de Reproducción Animal Córdoba. pp. 327 - 367. 
14. SAG, Servicio Agrícola y Ganadero. 2005a. Instructivo técnico para la vigilancia de la encefalopatia espongiforme bovina (EEB) en explotaciones bovinas expuestas directamente a las harinas de carne y hueso de Canadá. [En línea].

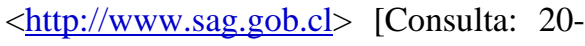
11-2010]

15. SAG, Servicio Agrícola y Ganadero. 2006b. Programa de bioseguridad para recintos feriales. Manual de procedimientos BIOSIF/MP1. Procedimientos de bioseguridad para recintos feriales. [En línea]. $<$ http://www.sag.gob.cl $>$ [Consulta: 2511-2010]

16. SAG, Servicio agrícola y ganadero. 2010c. Planteles de animales bovinos bajo certificación oficial. Instructivo Técnico $n^{\circ} 1$. Exigencias para el Ingreso al Programa de Planteles de Animales Bovinos Bajo Certificación Oficial [En línea]. $\quad<$ http://www.sag.gob.cl $>$ [Consulta: 20-01-2011]

17. SAG, Servicio Agrícola y Ganadero. 2004d. Programa Oficial de Erradicación de Brucelosis Bovina. Manual de procedimientos $\mathrm{N}^{\circ} 1$. "Procedimientos para la erradicación de brucelosis bovina” 16 p [En línea] $<$ http://www.sag.gob.cl $>$ [Consulta: 2511-2010]

18. Sanderson, M. W.; Dargatz, D. A.; Garry, F. B. 2000. Biosecurity practices of beef cow-calf producers. Special Reports. J. Anim. Vet. Med. Assoc. 217(2): 185189.

19. Sanderson, M. W.; Gnad, D. P. 2002. Biosecurity for reproductive disease. Vet. Clin. North. Am. Food. Anim. Pract. 18: 79-98

20. Tabel, J.R. 1998. Symposium: Biosecurity and disease. Johne's Disease: A Hidden Threat. J Dairy Sci. 81: 283288
21. Well, S. J.; Dee, S; Godden, S. 2002. Biosecurity for gastrointestinal diseases of adult dairy cattle. Vet. Clin. Food. Anim. 18: 35-55 


\section{Anexo I. Protocolo de Bioseguridad Predial}

\section{ESPECIFICACIONES TÉCNICAS DE BIOSEGURIDAD}

\section{Prevención del ingreso de agentes causantes de enfermedades}

\section{Ingreso de animales al predio}

- $\quad$ Se debe mantener un rebaño cerrado, evitando comprar animales, según el sistema productivo. Utilizando la inseminación artificial como alternativa para aumentar la masa e introducir genética, en sustitución del toro. Obtener reemplazos del mismo predio y evitar llevar a ferias y exposiciones a los animales.

- Si el sistema productivo requiere ingresar animales, la compra de animales debe considerar lo siguiente:

- $\quad$ Conocer el origen de los animales; para ello es preferible comprar animales directamente en el predio de origen y evitar realizar las compras a través de ferias de ganado. La compra de animales debe provenir de la menor cantidad de predios posible.

- $\quad$ Comprar en rebaños con status sanitario conocido, los cuales deben ser iguales o superiores al estatus sanitario de los animales propios.

- $\quad$ Conocer el programa de vacunación y el programa de control de parásitos aplicado en el predio de origen, desde el cual se requiera introducir animales al predio.

- Mantener los cercos en buen estado, de forma tal que se impida el ingreso indeseado de animales desde el exterior; y el contacto naso-nasal con animales ajenos al predio. En caso que fuese necesario se debe utilizar doble cerco.

- Evitar realizar pastoreos comunitarios con ganado de distintos predios, ajenos a la explotación.

Cuarentena

- Todos los animales que ingresan al predio, tanto animales nuevos como retornos (ferias, veranadas, exposiciones), deben someterse a un proceso de aislamiento o cuarentena, inmediatamente posterior a su arribo.

- La cuarentena debe habilitarse en una zona con bajo tráfico humano y/o vehicular, distante de fuentes de alimento y agua, y que evite la contaminación con estiércol. El corral debe estar físicamente aislado, alejado del resto de los animales, manteniendo una distancia mínima de 3 metros del rebaño, para evitar el contacto naso-nasal. Este aislamiento físico debe extenderse por 28 días, como mínimo.

- $\quad$ Los manejos realizados a este grupo (alimentación, suministro de agua, recolección de estiércol, etc.) deben realizarse por personal específico y/o programarse para ser realizados al final de la rutina del resto de los animales del predio, evitando interferir con el manejo del resto de los animales.

- El equipamiento a utilizar en el manejo de estos animales (pala, carro forrajero, etc.) debe ser de uso exclusivo, y restringido a esta unidad. En caso contrario, el equipo debe lavarse profusamente y desinfectarse, después de ser utilizado en la zona de cuarentena.

- Se debe realizar una observación diaria de los animales, con la finalidad de detectar en forma temprana alguna enfermedad. En caso de que algún animal presente signos de enfermedad, se debe aislar del resto de los animales y contactar al médico veterinario para que sea examinado.

- Se deben realizar manejos sanitarios del predio, de vacunación y desparasitación, tanto interna como externa, durante el periodo de cuarentena. Realizar exámenes diagnósticos, previa incorporación con el resto de los animales, de acuerdo al estatus sanitario del predio de destino.

- El establecimiento de cuarentena se debe limpiar y eliminar el resto de alimento, agua, heces y secreciones. En caso de que la instalación de cuarentena fuese un corral, deberá recolectarse el 
estiércol, realizar la limpieza de bebederos y comederos y en lo posible permanecer sin uso por un período mínimo de 6 meses.

\section{Ingreso de personas ajenas al predio}

- Se debe instalar señalización que indique la prohibición de ingresar al predio sin autorización, (Ejemplo: letreros de "No entrar"), con un teléfono de contacto, e indicar las entradas al predio y las oficinas. Destacar la condición del predio y las normas mínimas que deben respetarse al ingresar a las instalaciones.

- $\quad$ Establecer un acceso restringido y controlado hacia el plantel. Se debe mantener un registro de las visitas al predio, con el nombre del visitante y la fecha de su visita. Esto, con la finalidad de detectar el origen de un posible brote infeccioso en el rebaño.

- Determinar si las personas han estado en otros predios previamente. En caso que el visitante sea extranjero, se debe preguntar el país de origen, si ha estado en otros predios en su país de origen o en otro país, y en caso de haber estado en otro predio en un país con una enfermedad infecciosa exótica, en los 5 días previos, se debe restringir la visita.

- Los visitantes deben ingresar al plantel usando botas limpias y ropa de protección. En caso de no presentarlas, se debe proveer botas de plástico botas o protectores de calzado de plástico y overoles a los visitantes.

- $\quad$ Proveer un pediluvio con una solución desinfectante adecuada y con una escobilla, a la entrada del recinto. Mantener este pediluvio limpio diariamente, remover la acumulación de materia orgánica y rellenar regularmente con desinfectante. Insistir que las personas que ingresan a la explotación laven sus botas antes del ingreso y salida del predio.

- Restringir el ingreso a áreas de alimento e instalaciones animales, sólo a las personas a cargo del ganado. Evitar que los visitantes toquen al ganado y se contaminen con estiércol. En lo posible delimitar territorialmente aquellas áreas específicas a visitar y/o recorrer, a objeto de minimizar contactos.

\section{Ingreso de vehículos}

- Se debe restringir el ingreso de vehículos, autorizando sólo la entrada a vehículos que forman parte o integran el sistema productivo.

- $\quad$ Antes de ingresar a la explotación, los vehículos deben pasar por un rodiluvio y/o someterse a un proceso de lavado y desinfección de los neumáticos y de la zona inferior del vehículo. El rodiluvio debe mantenerse limpio, con una remoción constante de la eventual acumulación de materia orgánica; y una reposición programada del desinfectante, para asegurar su efectividad.

- Delimitar y señalizar un área de estacionamientos, ubicada en la periferia del predio y alejada de las instalaciones animales, bodegas e instalaciones de alimento, y en sectores donde se evite la contaminación con estiércol.

- $\quad$ La ubicación de carga/descarga de alimento y el cargadero de animales con su corral, deben estar emplazadas en una zona alejada del rebaño y sus instalaciones, de preferencia ubicada en la periferia del predio para evitar que los camiones ingresen o egresen con patógenos.

- Establecer "rutas limpias" para evitar que los vehículos que ingresen al predio (Entrega de alimento, transporte de animales, vendedores, médicos veterinarios) entren en contacto con la zona de alimentos, instalaciones de animales y que se contaminen con estiércol.

\section{Prevención de la diseminación de agentes causantes de enfermedades}

\section{Manejo sanitario}

- Instaurar un plan de vacunación y de control parasitario, por escrito, con la ayuda de un médico veterinario, con el fin de tener una adecuada estrategia de control de enfermedades, que se adecue a las exigencias de bioseguridad del productor; así como también a las exigencias sanitarias a nivel nacional.

\section{Manejo de equipos}

- Utilizar mangas de palpación para realizar exámenes y/o tratamientos ginecológicos. La utilización de las mangas debe ser individual por animal. 
- Utilizar agujas y jeringas desechables, sólo una vez, cuando se administren tratamientos y vacunas a los animales.

- Equipos e instrumentos que tengan contacto directo con el animal (descornadores, equipo de castración, despalmadores, equipo de implantes, cuerdas, sondas etc.) deben limpiarse y desinfectarse (esterilizar cuando corresponda) entre cada animal para evitar transmisión de enfermedades dentro del rebaño.

\section{Manejo de animales enfermos}

- $\quad$ Los animales que presenten signos de enfermedad deben separarse y mantenerse en una instalación de enfermería, la cual debe ser utilizada exclusivamente para dicho fin. Una vez que los animales se han recuperado deben volver al grupo original.

- $\quad$ El corral de enfermería debe estar aislado e impedir el contacto con el resto de los animales del rebaño. Una vez utilizado se debe limpiar y eliminar el resto de alimento, agua, heces y secreciones. Este corral no debe utilizarse como maternidad.

- Debe mantenerse un registro de los animales enfermos y el tratamiento aplicado. En el registro se debe incluir la identificación del animal o grupo de animales tratados, fechas de tratamiento, producto utilizado y número de serie, vía de administración, dosis entregada, período de resguardo y el nombre de quien realice el tratamiento.

- Los manejos tanto de alimentación, suministro de agua y remoción de estiércol, como aplicación de tratamientos a los animales enfermos, deben realizarse por personal específico que no tenga contacto con otros bovinos, o realizar las tareas al final del manejo de los animales del rebaño propio.

- Los equipos y utensilios utilizados para el tratamiento de los animales enfermos deben ser debidamente limpiados y desinfectados (esterilizados cuando corresponda), después de su uso en el animal enfermo.

- Se debe tener conocimiento de los signos de enfermedades exóticas no presentes en el país como fiebre aftosa y EEB. En caso que se presente alguno de estos cuadros, se debe avisar inmediatamente al veterinario encargado o a la autoridad sanitaria correspondiente.

- Se debe reportar al veterinario, cualquier enfermedad que afecte a una gran proporción de los animales del rebaño y/o animales enfermos por causas desconocidas

\section{Manejo de los animales muertos}

- $\quad$ Los animales muertos sin razón aparente deben someterse a procedimientos de necropsias y/o toma de muestras, realizadas por el veterinario.

- Los animales muertos deben removerse rápidamente del lugar desde donde fallecieron con la finalidad de evitar al máximo el contacto con otros bovinos y otras especies como aves, perros, gatos. Los animales muertos deben eliminarse en un período no superior a 48 horas de producida su muerte.

- $\quad$ El proceso de eliminación puede desarrollarse mediante el entierro, incineración o realización del compostaje del cadáver y/o restos de animales.

\section{Manejo reproductivo}

- Los reproductores deben ser testeados regularmente con la finalidad de detectar cualquier enfermedad que afecte el rendimiento reproductivo (tales como campilobacteriosis, tricomoniasis, etc.)

- La utilización de toros (cuando corresponda) debe ser restringida en forma exclusiva al interior del plantel. Se debe evitar facilitar y/o intercambiar toros con otros predios.

- Separar y/o trasladar a las vacas que están próximas a parir a pasturas/corrales limpios, protegidas de las inclemencias del tiempo (según corresponda). Estas pasturas/corrales no deben permitir el contacto con el resto de los animales del rebaño y deben utilizarse en forma exclusiva para dicho fin.

\section{Manejo de alimentos y agua}

- Inspeccionar cada partida de alimento recibida y propia. Realizar análisis de calidad, microbiológico, micotoxinas y toxicológico, tanto al alimento comprado como al propio.

- Se debe tratar las pasturas destinadas a consumo animal con fertilizantes, herbicidas y plaguicidas, en forma tal que se prevenga cualquier riesgo para el animal. 
- Asegurar la entrega de una ración balanceada a distintos grupos de animales, por medio de la elaboración de una dieta con asesoría profesional.

- $\quad$ Establecer instalaciones de almacenamiento de alimento que impidan el ingreso de otras especies animales, como aves, roedores, perros, gatos, moscas, entre otros. El ingreso a estas instalaciones debe ser restringido, ingresando exclusivamente personal encargado de la alimentación, con la finalidad de evitar contaminación del alimento con estiércol y/o secreciones animales. Se debe prevenir la contaminación del alimento con químicos, pesticidas y medicamentos.

- Suministrar cantidad de agua adecuada para el número de animales de cada corral y chequear la calidad del agua, a través de análisis microbiológicos y químicos; evitar que se contamine con heces y orina, tanto de bovinos como otras especies (perros, roedores, aves, etc.)

- Utilizar comederos y bebederos de forma y tamaño adecuados para que sean fáciles de limpiar, que impidan la contaminación con estiércol y que a la vez estén proporcionados a la masa de animales de cada corral. Limpiar los comederos y bebederos (y/o cursos de agua) en forma periódica.

- No alimentar al ganado con alimentos proveniente de o que contengan proteína de origen rumiante. Evitar alimentar al plantel con residuos (sobrante) de la alimentación de vacas lecheras; en caso que esto no fuese posible, alimentar con este alimento exclusivamente a los animales adultos

\section{Manejo preventivo de enfermedades}

- Evitar el contacto del ganado bovino con otras especies animales presentes en el predio. Tanto especies productivas como bovinos de leche, ovinos, caprinos, cerdos, aves de corral, camélidos; así como animales domésticos como perros, gatos, y eventualmente animales silvestres.

Manejo de grupos de producción

- Mantener los grupos de animales, lo más permanente posible, evitando intercambios de animales entre diferentes grupos. Se debe tratar de disminuir el contacto entre bovinos de distintos grupos dentro del rebaño; evitar el contacto de los animales jóvenes con los adultos; así como también la contaminación cruzada de alimento, agua y estiércol.

- Limpiar las áreas de confinamiento una vez que los animales han dejado dicha instalación, eliminando restos de alimento, estiércol, y en lo posible dejarlo sin uso por dos meses.

\section{Control de mascotas}

- $\quad$ Controlar el movimiento de perros y gatos dentro y entre predios.

- Minimizar el contacto de perros y gatos con el ganado, en especial en situaciones que los bovinos realicen descargas de secreciones (muertes, enfermedades, partos, manejos habituales, etc.) y con alimentos (bodegas, silos, comederos, bebederos).

- Las mascotas deben mantenerse con sus programas de vacunación y desparasitación actualizado.

Peligros químicos

- $\quad$ Los pesticidas y plaguicidas deben almacenarse en instalaciones seguras, con acceso restringido.

- Los desechos químicos (pesticidas, drogas, etc) deben ser eliminados adecuadamente, evitando el contacto con animales y fuentes de agua de los animales (envases vacíos, remanentes, entre otros)

\section{Control de plagas}

\section{Control de Moscas}

- $\quad$ Se debe contar con un plan para el control de moscas, según el nivel de riesgo que presente el plantel. Este plan debe registrarse, indicando las medidas de control y los insecticidas utilizados.

- Se debe utilizar insecticidas específicos para bovinos, los cuales pueden aplicarse en distintas formas (aretes, bolsas de polvo o de aceite, "pour on", Spray, alimento con larvicida, entre otros).

- $\quad$ En las instalaciones se deben aplicar insecticidas ambientales (fumigación espacial o spray residuales, trampas o cebos) y/o controles biológicos. 
Paris A. et al.

Control de Roedores

- $\quad$ Desarrollar un plan de control de roedores, de acuerdo al grado de infestación presente en el plantel. En este plan deben indicarse las medidas de control y los métodos seleccionados (rodenticidas utilizados, ubicación de los cebos, trampas entre otros.).

- Suprimir los lugares de ingreso de los roedores a las construcciones del plantel, en especial a las áreas de almacenamiento de alimento. Eliminar los posibles lugares de anidación y guarida.

- Mantener los alimentos susceptibles (granos, principalmente) en contenedores a prueba de roedores. Reducir el derrame de alimento y eliminar fuentes de agua como cañerías rotas, goteras, estanques.

\section{Control de Aves}

- $\quad$ Desarrollar un plan de control de aves, en predios donde se consideren una plaga. En este plan deben indicarse las medidas de control y los métodos seleccionados (repelentes, espantapájaros, agentes letales, entre otros)

- $\quad$ Eliminar lugares de entrada y anidamiento de las instalaciones, en especial de las bodegas de alimento. Se deben sellar todas las aberturas en los techos y revisar los posibles lugares de anidamiento en cornisas, vigas, perchas, etc.

\section{Manejo de estiércol}

- Se debe tener un plan de manejo de estiércol que evite la contaminación ambiental, de las fuentes de aguas superficiales y profundas. Se debe evitar repartir el estiércol fresco, en pasturas utilizadas para pastoreo de forraje u heno.

- El estiércol debe removerse una vez que los animales hayan abandonado el corral. En caso contrario se debe remover el estiércol constantemente de los corrales, para evitar que se complete el ciclo de las moscas y parásitos.

- El estiércol debe acumularse en una zona alejada del contacto con los animales. El estiércol puede mantenerse en pilas, siempre que se desarrolle una costra dura en la superficie, lo que reduce la ovispostura de moscas.

- Realizar tratamiento al estiércol bajo condiciones que destruyan la mayor parte de las bacterias que producen enfermedades (p.e. compost). El periodo mínimo de espera posterior a la diseminación de estiércol, corresponde a 1 mes.

\section{Manejo de maquinaria y equipos}

- De preferencia utilizar equipos y maquinaria propios y evitar facilitarlo a predios vecinos. En caso que no fuese posible, hay que lavar y desinfectar minuciosamente el interior y el exterior los equipos compartidos, antes de salir y antes de retornar al predio, y exigir que retorne limpio al predio.

- Los equipos destinados para manejos de alimentación (cargadores, carros forrajeros, tractores, palas, horquetas, etc.) deben utilizarse exclusivamente para dicho fin. Si el equipamiento para alimentación es utilizado para otras tareas, como remoción de estiércol o animales muertos, éste debe lavarse y desinfectarse entre sus usos.

- $\quad$ Rutinariamente los equipos y maquinaria, tanto para manejar alimento como para manejar estiércol y animales muertos, deben someterse a un proceso de desinfección.

\section{Prácticas de trabajadores}

- Se debe capacitar a los trabajadores, respecto a la bioseguridad predial, se debe entregar información respecto a su significado, los beneficios, y la forma de aplicar los principios de bioseguridad a las prácticas de manejo del predio. Se deben comprometer a aplicarlas.

- Los trabajadores deben tener hábitos de higiene apropiados para evitar la transmisión de enfermedades desde y hacia el rebaño. Deben evitar conductas como defecar, orinar y escupir en las dependencias de los animales y alimento.

- Los trabajadores deben disponer de ropa adecuada para trabajar en el predio, overoles y botas, los cuales deben lavarse periódicamente en el predio, en lo posible, con una solución desinfectante. Esta ropa de 
trabajo no debe salir de la explotación, por lo que los trabajadores deben disponer de servicios sanitarios adecuados que les permitan lavarse y ducharse.

- Se debe utilizar guantes/mangas y ropa de protección en cualquier situación de riesgo de contacto con descargas del animal o tejidos animales (palpaciones, partos, necropsias, castraciones, entre otros).

- Los trabajadores deben lavar sus manos y brazos, cambiar su ropa de trabajo y lavar sus botas después de tratar animales enfermos.

\section{Prevención de la salida de agentes causantes de enfermedades}

\section{Salida de animales y vehículos}

- Se debe evitar realizar movimientos de animales, que impliquen la salida de éstos hacia otros predios (Ej: intercambios de reproductores)

- $\quad$ Se debe evitar transportar animales que se encuentran con signos aparentes de enfermedad, a otros predios o ferias de ganado. Los animales que se encuentran con enfermedades terminales o crónicas deben enviarse directamente al matadero o sacrificarse en el plantel.

- Al salir de la explotación los vehículos deben pasar por un rodiluvio y/o someterse a un proceso de lavado y desinfección de los neumáticos y de la zona inferior del vehículo. El rodiluvio debe mantenerse limpio, con una remoción constante de la acumulación de materia orgánica y con una reposición adecuada del desinfectante. 